\section{Infection prevention and control practices in long-term residential care settings: a multiple methods approach}

Claudia KY Lai ${ }^{1}$, Audrey PY Leung ${ }^{1}$, Rainbow LP Lee ${ }^{1}$, Enid WY Kwong ${ }^{2}$, Rick YC Kwan ${ }^{1}$, Patrick PK Kor ${ }^{1}$, Annie Chung, ${ }^{3}$ Justina YW Liu ${ }^{1}$

\begin{abstract}
Background. Despite the relatively high risk of infection in long-term residential care settings, few studies have provided a complete evaluation of infection prevention and control (IPC) practices. Therefore, we aimed to evaluate IPC practices in two nursing homes in Hong Kong in order to inform care providers and enhance the overall quality of care.
\end{abstract}

Methods. This study was conducted between August 2015 and March 2016. The IPC practices of two nursing homes were evaluated using a multiple-methods design that includes field observations, focus group interviews of staff (administrators, nurses, allied health professionals, health workers, and personal care workers), and document reviews of residents' records and relevant practice guidelines of the Social Welfare Department and the Department of Health of Hong Kong.

Results. Based on field observations, the two nursing homes met the IPC guidelines $80.4 \%$ and $75.0 \%$ of the time, respectively. The cleansing and disinfection of the environment and facilities were satisfactory. For focus group interviews of staff, 22 women and one man aged 35 to 59 years participated. The staff could describe the IPC measures satisfactorily. Yet what was described was not always observed to be done. No specific infection incident of interest was reported between January and December 2014. Overall, there are five areas of practice that deserve attention: long-term indwelling catheter care, naso-gastric feeding, respiratory care, hand hygiene, and care of residents and equipment on oxygen therapy.

Conclusion. Areas in need of improvement included observance of the practice of handwashing, the provision of better handwashing facilities, the proper use of gloves, and the maintenance of the residents respiratory hygiene when dining, the prevention of myiasis, and the use of better bedside alert signage. We recommend that nursing homes establish an IPC committee and assign an IPC officer to oversee IPC practices. The findings enable residential home operators to identify and prioritise the areas of care that need to be addressed in the context of IPC.

Key words: Hand hygiene; Infection control; Nursing homes, Practice guidelines; Residential facilities; Standard of care

\section{ORIGINAL ARTICLE}

\footnotetext{
School of Nursing, Hong Kong Polytechnic University

2 Centre for Gerontological Nursing, Hong Kong Polytechnic University

Social Services Department, Yuen Yuen Institute
}

Correspondence to: Prof Claudia Lai, Honorary Professor, School of Nursing, The Hong Kong Polytechnic University, Hung Hom, Kowloon, Hong Kong SAR. Email: claudia.lai@polyu.edu.hk 


\section{INTRODUCTION}

Residential home living is characterised with living in close quarters, having multiple formal care providers, and engaging in group-based activities. A confined environment, high staff turnover, and limited staff education and training may affect compliance with infection-control guidelines in nursing homes. ${ }^{1}$ Nursing home residents often have multiple comorbidities and are at an increased risk of infection, resulting in increased morbidity, mortality, and hospital admissions..$^{2-4}$

The incidence and prevalence of infections in nursing homes are difficult to ascertain because of the diverse health profiles of people in long-term residential care. ${ }^{4}$ Diagnoses are often delayed in older people because of inadequate fever response, lack of specific symptoms, and difficulty in collecting specimens. ${ }^{5}$ The prevalence of overall infections in nursing homes varies widely from $1.6 \%$ to $32.7 \%{ }^{3,6,7}$ In Hong Kong nursing homes, the prevalence of infection has been reported to be $2.7 \%$ to $5.7 \% .8,9$ Common endemic infections in nursing homes are urinary tract, respiratory, skin, and soft tissue infections, and in long-term care settings are gastroenteritis, influenza, and skin infections. ${ }^{3}$

Studies of infection prevention and control (IPC) practices in long-term care homes tend to focus on particular conditions such as catheter-associated urinary tract infections, ${ }^{10}$ transmission of multidrug resistant organisms, ${ }^{11}$ hand hygiene practices, ${ }^{12}$ and enteral feeding. ${ }^{13}$ However, studies providing an overall evaluation of IPC practices are lacking. Therefore, we aimed to evaluate IPC practices in two nursing homes in Hong Kong using a multiple-methods design in order to better inform service providers on how to enhance the overall quality of care.

\section{METHODS}

This study was approved by the Human Subjects Ethics Application Review Committee of Hong Kong Polytechnic University (HSEARS20150422006) and conducted between August 2015 and March 2016. Written informed consent was obtained from each participant. Confidentiality and anonymity of data were ensured. A multiple-methods design ${ }^{14}$ was used and included field observations, focus group interviews of staff, and document reviews. The design is expected to produce findings that are more robust than those obtained in single-method studies..$^{15}$

Two nursing homes for the elderly were evaluated: home A with 55 beds and home B with 150 beds. The two nursing homes are subsidised by the government and managed by a non-governmental organisation (NGO). They offer residential care, meals, personal care, and nursing care for older adults who are unable to care for themselves but are mentally suited for communal living. ${ }^{19}$

Staff members of different seniority and experience were invited to participate in focus group interviews, including administrators, nurses, allied health professionals, health workers, and personal care workers.

Residents'records were reviewed, as were relevant practice guidelines for nursing homes, namely the Code of Practice for Residential Care Homes (Elderly Persons) from the Social Welfare Department, ${ }^{17}$ and The Guideline on Prevention of Communicable Diseases in Residential Care Home for Elderly (3rd Edition) from the Department of Health of Hong Kong. ${ }^{18}$

\section{Field observations}

Field observations provide first-hand information on the participants' behaviours, body language, and verbal interactions, allowing researchers a better understanding of the situation. Field observations can be used to verify data collected through other methods. ${ }^{16}$

Observations included the environment such as the outdoor and open areas, living rooms, dining room, common activity rooms, toilets, common bathrooms, laundry, and isolation corners. Attention was paid to IPC-related activities including making beds, serving meals, delivering special programmes (group exercise and dementia training), taking residents to the bathroom, preparing for diaper rounds, preparing residents for bedtime, preparing meals (by the cook), cleaning the outdoor areas, collecting waste, and disinfecting the furniture. Observations also included the use, cleansing, and storage of clinical equipment such as the diaper trolley, bath trolley, bathroom equipment, tubefeeding trolley, and medication trolley. Clinical procedures observed included administration of 
medications and topical ointments and nasogastric tube feeding.

There was a 1-week desensitisation period before field observations so that residents and staff were not mindful of the research personnel.

On dates between 17 August and 9 October 2015 selected at random, from 08:30 to 18:00, research personnel conducted observations of staff in common and public areas. Research personnel were declined observations in residents' private settings.

Practices that raised questions were recorded on field notes; no interference was made. Comments from residents on the ventilation in the living room and the frequency of washing floors were recorded, as were remarks from staff on the compliance of residents with cough etiquette and hygiene practices. The research personnel did not encounter changing of dressings, emptying of urine bags, or continuous ambulatory peritoneal dialysis. In all, 52.25 hours of observations were made.

Any observed procedure was counted as one item (ie, the administration of drugs to a resident). The performance of each item was categorised as satisfactory or unsatisfactory, depending on whether the relevant standard of practice was met. The percentage of items meeting the relevant standard of

TABLE 1

The semi-structured focus group interview guide

Understanding of the infection control practice

Based on your daily duty in the home, what do think about the infection control practices?

Would you please give an example(s) about your daily infection control practices?

Are you aware if there are infection control guidelines and policies in the Home? If yes, do you understand them?

Did the guidelines and policies guide you to prevent infections in your daily work? How?

Self-appraisal

Can you share your experience how you prevent infections at work?

Was there a situation in which you did not follow the infection control guidelines? Why did it happen?

What are the possible consequences if you do not follow the guidelines (please give an example)?

Evaluation of infection control practices

What are your concerns with regard to preventing infections in the Home?

What can be done to deal with these concerns?

What can be done to improve infection control in the Home? practice was calculated.

\section{Focus group interviews of staff}

Three sessions of focus group interviews of staff were conducted between 8 and 17 December 2015 by a nursing professor and a research assistant, using a semi-structured interview guide (TABLE $\mathbf{1}$ ). Frontline staff were interviewed separately from management staff. Qualitative data were analysed using qualitative content analysis. ${ }^{20}$ Interviews were recorded and transcribed verbatim. Data were broken down into smaller meaning units and categorised with reference to the semi-structured interview. Data collection continued until no new findings were derived. Data were independently coded by three team members. Intercoder reliability was achieved by in-depth discussions on interpretation. Differences were resolved by further deliberation or input from other co-investigators until a consensus was reached.

\section{Document reviews}

On 3 March 2016, documents from January 2014 to March 2016 were reviewed, including long-term care services delivery system assessment records from the Social Welfare Department, the nursing homes' own admission assessment records, individual care plans, medical examination forms, hospital discharge summaries, community geriatric assessment services notes, visiting medical officer's notes, nursing notes, and vital signs observation charts. The incidence of infections in terms of respiratory infections (pneumonia and influenza in particular), urinary tract infections, diarrhoeal illnesses, and skin and soft tissue infections (eg, scabies) between January 2014 and December 2014 was determined.

\section{Data analysis}

Findings from the three different sources were tabulated and compared and then discussed at regular (biweekly to monthly) meetings until consensus was reached. Frontline staff were consulted when there were questions related to care practices. Triangulation of findings enabled counter-check and verify of data so as to enhance the comprehensiveness and objectivity of the data analysis.

\section{RESULTS}

\section{Field observations}

Homes A and B met the standard of the Department of Health guidelines $80.4 \%$ and $75.0 \%$ of the time. 
TABle 2 shows the areas needing improvement, including measures to promote the personal respiratory and hand hygiene of the residents (eg, no supply of handrubs or tissue paper on the dining table), staff practices in terms of maintaining standard precautions to prevent infections (eg, urine bags touching the wheels of a mobility chair, residents sitting shoulder-to-shoulder at the dining table), standard procedures in providing environmental cues as part of standard precautions (eg, issuing notices to alert staff and residents to observe the practice of handwashing), and following protocols for environmental cleaning (eg, putting dirty diapers on the floor).

\section{Focus group interviews}

22 female and one male staff members (three registered nurses, three enrolled nurses, one physiotherapist, four health workers, nine personal care workers, and three workmen) aged 35 to 59 years with work experience of $<1$ year to $>6$ years took part in an interview. A total of three 1-hour interviews were conducted. Home A asked to have a mixed-group interview because of a small pool of staff. Findings are presented according to the 2015 Department of Health guidelines on the prevention of communicable diseases in residential care homes for the elderly (TABLE 3).

The frontline staff had adequate support from management in terms of providing sufficient supplies. They had to regularly update their IPC knowledge. Senior staff regularly supervised other staff over the IPC practices. The staff generally could describe IPC measures for residents and visitors and special IPC measures for those who had been newly admitted or those who were carriers of methicillinresistant Staphylococcus aureus (MRSA). The staff of home B could identify the staff in charge of IPC information and measures, although they lacked

TABLe 2

Areas needing improvement based on field observations

\begin{tabular}{|c|c|}
\hline $\begin{array}{l}\text { Department } \\
\text { of Health } \\
\text { guidelines }\end{array}$ & Area needing improvement \\
\hline \multicolumn{2}{|c|}{ Home A } \\
\hline 3.1 .1 & Residents' personal hygiene: hand hygiene: no supply of handrubs on the dining table \\
\hline 3.1 .2 & $\begin{array}{l}\text { Residents' personal hygiene: respiratory hygiene and manner of coughing: no tissue paper on the dining table and a } \\
\text { resident's mouth was not covered by a mask when sleeping (at risk of myiasis [infection from fly larva]) }\end{array}$ \\
\hline 4.1 .2 & Standard precaution: respiratory hygiene: residents were not protected from inhaling dust when beds were made \\
\hline 4.1 .3 & $\begin{array}{l}\text { Standard precaution: personal protective equipment: gloved hands/use of gloves: a nurse administered medication } \\
\text { with gloved hands using non-latex gloves }\end{array}$ \\
\hline 4.1 .4 & $\begin{array}{l}\text { Standard precaution: cleaning and disinfecting the environment: a personal care worker was seen placing dirty } \\
\text { diapers on the floor on one occasion }\end{array}$ \\
\hline 4.5 .1 & Prevention of urinary catheter-associated infection: a urine bag outlet touched the wheel of a geriatric chair \\
\hline 4.5 .2 & $\begin{array}{l}\text { Nasogastric tube feeding: a health worker did not use a pH indicator to test the position of a nasogastric tube but } \\
\text { used a 'whoosh test' instead. }\end{array}$ \\
\hline \multicolumn{2}{|c|}{ Home B } \\
\hline 1.6 .3 & Prevention of the spread of infections: residents sat shoulder to shoulder with each other along the dining table \\
\hline 3.1 .1 & $\begin{array}{l}\text { Hand hygiene: lack of handwashing facilities and handrubs for residents, especially in common areas (eg, dining room } \\
\text { and TV corner) }\end{array}$ \\
\hline 4.1.1 & $\begin{array}{l}\text { Standard precaution: hand hygiene: lack of handwashing facilities or handrubs for staff (except in the pantry and } \\
\text { the resident's toilets); staff seldom washed or rubbed hands with alcohol handrubs (eg, prior to serving meals), but } \\
\text { they could have already done so without the observer's knowledge); a lack of proper hand hygiene before instilling } \\
\text { eye drops were observed in a few occasions (ie, the staff member walked directly to the resident to give eye drops } \\
\text { without washing hands) }\end{array}$ \\
\hline 4.1 .3 & $\begin{array}{l}\text { Standard precaution: use of personal protective equipment: the staff wore gloves on unnecessary occasions (eg, } \\
\text { serving dessert) }\end{array}$ \\
\hline 4.3 & $\begin{array}{l}\text { Isolation measures (in own room): lack of notice to alert staff and residents to observe the practice of handwashing } \\
\text { and no handrubs nearby; no isolation room in one of the floors, but that could be due to the lack of space }\end{array}$ \\
\hline 4.5 .3 & $\begin{array}{l}\text { Prevention of pressure ulcers and wound infections: positioning of bedridden residents did not match the turning } \\
\text { schedule posted at the head of the bed; records of turning not seen }\end{array}$ \\
\hline 4.5 .1 & $\begin{array}{l}\text { Prevention of urinary catheter-associated infection: inconsistent data on urethral swabbing: focus group interview } \\
\text { revealed differences in practice between professional and non-professional staff. Some said that swabbing was } \\
\text { practised, others said there was no need to do swabbing for catheter care. The senior nurse clarified that swabbing is } \\
\text { not a part of the catheter care guidelines. }\end{array}$ \\
\hline
\end{tabular}


information about the need to set up an infection control committee and about the role of an infection control officer. Information about catheter care was inconsistent: a professional staff in home B mentioned that swabbing was performed twice a day using Hibitane (chlorhexidine), whereas nonprofessional staff said that no swabbing was needed if the resident had been bathed.

\section{Document review}

12 of 19 residents in home $A$ and 128 of 147 residents in home B consented to have their documents/records reviewed. No specific infection incident of interest was reported between January and December 2014. Five (3.6\%) of 140 participating residents aged 66 to 93 years were at higher risk of contracting infections because they had multiple chronic illnesses and had received invasive care interventions involving an indwelling urinary catheter $(\mathrm{n}=2)$, a nasogastric feeding tube $(n=1)$, a nasal oxygen cannula $(n=1)$, or a wound with MRSA $(n=1)$. One resident with diabetes had an episode of pneumonia in 2015. The possibility of cross-infection could neither be confirmed nor excluded. Nevertheless, the nursing care for monitoring diabetes and for managing pressure sores was of good quality (early detection and prompt referral to a doctor or hospital). The frontline staff could detect signs and symptoms of urinary tract infection, respiratory tract infections, and/or other medical illnesses early and sought timely medical attention.

\section{Triangulation of findings}

The cleansing and disinfection of the environment and facilities based on field observations were satisfactory. The knowledge, hand hygiene, and respiratory hygiene based on focus group interviews were good. Nonetheless, there were discrepancies between field observations and focus group interviews. For instance, it was mentioned that gloves were changed and disposed of after use in bathing for each resident. However, field observations revealed that personal care workers wore long yellow plastic gloves and did not change them in between bathing different residents.

The staff reported appreciation of the support given by the management in terms of providing adequate supplies and updating IPC information and knowledge regularly. They were aware that they needed to be kept up-to-date. Staff were able to describe IPC measures for the residents and their visitors and special measures for those who had been newly admitted or those who were MRSA carriers. However, they lacked information about the need to set up an infection control committee or to appoint an infection control officer, although the staff of Home B could identify the person in charge of IPC information and measures.

Overall, there are five areas of practice that deserve attention: long-term indwelling catheter care, nasogastric feeding, respiratory care, hand hygiene, and care of residents and equipment on oxygen therapy (TABLE 2). Two commendable practices were noted: the nursing care for monitoring diabetes and managing pressure sores.

\section{DISCUSSION}

Both nursing homes mostly complied with the IPC guidelines of the Social Welfare Department and the Department of Health. Home A had a slightly higher level of compliance than home B. However, home B has more beds, more staff, and therefore more ongoing activities. To prevent infections in long-term care facilities, the standard procedures for environmental cleaning, prevention of outbreaks, hand hygiene, and food preparation should be followed. ${ }^{21}$ The two nursing homes attained a satisfactory to good report on environmental cleaning and hand hygiene; food preparation was not evaluated.

In nursing homes in the United States, the lack of adequately trained personnel is a crucial area that needs to be addressed in IPC. ${ }^{23}$ However, education alone does not change handwashing behaviour. ${ }^{23}$ Knowledge about IPC practices is not associated with higher compliance. ${ }^{25}$ In a high-fidelity simulation study, standard education techniques do not lead to better compliance. ${ }^{26}$ Video feedback may reinforce learning of the correct practices. In a study on certified nursing assistants, hands-on training and on-the-spot training are effective strategies for overcoming barriers in IPC. ${ }^{27}$ The two nursing homes had on-the-spot supervision and regular training, and thus acceptable performance in IPC.

Compared with clinical audit, direct observation is the preferred auditing method despite having the Hawthorne effect. Unobtrusive observations can reduce the Hawthorne effect. ${ }^{27}$ Our team was careful 
TABLE 3

Findings from focus group interviews of staff based on the Guidelines on the Prevention of Communicable Diseases in Residential Care Homes for the Elderly issued by the Department of Health

\footnotetext{
Home management and team work

The staff of both homes stated that they had a sufficient supply of materials for daily use. They were pleased about their working relationships. At home B, the nurses reported working with the physiotherapist and social worker as a team to contain the spread of cases of infection or suspected infection.
}

Training and in-service education

The staff of both nursing homes were kept informed of up-to-date practices on infection control and prevention. They were required to submit their annual in-service education records to management.

Supervision

Supervision of daily practices was conducted on the spot by nurses on health workers and personal care workers. More structured supervision was conducted by the senior nurses, who would supervise their subordinates one by one on an annual basis. The items needing regular checking included diluting Clorox, putting on personal protective equipment, and handwashing. For home $\mathrm{B}$, a general round on each floor by the senior nurse and the superintendent took place daily. Despite the stress that might have been induced by these supervisory activities, the staff expressed their acceptance of and adaptation to these events.

Infection control committee

The staff of home A had no idea what the terms 'infection control committee' or 'infection control officer' meant. Home B staff were aware that there was an infection control committee.

Measures for residents for infection prevention and control

The staff of both nursing homes stated that they were required to help the residents to clean their hands with handrubs or to wash their hands before each meal. They also stated that the following practices were carried out: (1) isolation of residents discharged from the hospital for 3 to 4 days to contain possible infection brought in from the hospital, (2) isolation of residents with influenza and fever in their own rooms, and (3) residents are given an explanation of hand hygiene to gain their acceptance and compliance.

Measures for visitors/family members for infection prevention and control

Both nursing homes had taken measures to restrict people from visiting residents who were under isolation. The pre-requisite for visitors to enter the nursing homes included wearing a mask and proper handwashing. The staff said that posters explaining infection control measures were posted in areas where they would catch the eye, and that the measures were explained to the visitors to promote compliance.

Staff daily practice on infection prevention and control

The staff of both nursing homes stated that they used AP5, a user-friendly disinfectant for the environment, to clean the furniture and air, and that household waste was discarded on a daily basis, and that clinical waste was put in red plastic bags, which were then put into specifically assigned boxes. Regular collection for proper disposal of clinical waste was outsourced to a registered company. Several types of gloves were used for different types of cleansing procedures including bathing residents, daily household cleaning, and collecting used utensils/tableware. Home A staff said that they cleaned their hands with alcohol handrubs before and after taking care of residents.

Care practices for specific groups of residents

Care of residents with urinary catheter

Professional staff in home B mentioned that standards of practice were in place, including changing the catheter and emptying the urine bag. Professional staff in home A did not mentioned such information. The frontline staff of both nursing homes said that they had set routines for changing the catheter and emptying the urine bag.

Care of residents requiring naso-gastric tube feeding

The staff of both nursing homes were knowledgeable about the clinical care required for this procedure.

Care of residents with tinea unguuium (home B)

Professional staff in home B mentioned that the management of such residents included providing medical consultations, cutting their nails, and consulting a podiatrist if necessary. The non-professional frontline staff mentioned that each resident wore their own slippers and socks. Cross use was prohibited.

Care of residents with methicillin-resistant Staphylococcus aureus

Home B staff mentioned that residents who were carriers were put last on the bathing list. Bathing equipment were disinfected thoroughly after their use. The professionals mentioned that reminders such as hand hygiene and gloving the hands were posted at the head of the affected residents' bed. They also mentioned that alcohol swabs, gloves, and handrubs were placed at each resident's bedside for easy access.

Care of newly admitted residents

The staff of both nursing homes mentioned that a skin assessment and a shower were performed upon admission to all newly admitted residents for the early detection and treatment of clinical problems.

to desensitise the staff and residents to the presence of research personnel before actual field observations. The two nursing homes invited our team to evaluate their practices to improve the quality of care. The service managers responsible for long-term care services reported that changes were already being made as the study progressed. The professional and managerial staff became more acceptable to quality 
improvement projects. The frontline staff reported that participation was not as discomforting as they had initially imagined. They worked well with the research personnel and felt respected. Such an attitude brought changes in future. They became to understand that all staff members should be held accountable for the care provided and subjected to monitoring and regular appraisals. The managers believed that it would become easier for the management to introduce changes in practice based on evidence.

There are limitations to this study. Data collected from field observations were opportunistic and should be interpreted with caution. Nearly all relevant observed items were only shown once, and observations were made on a limited number of staff members and residents. The focus group interviews of staff and the document review addressed such a weakness, and the findings were cross-validated.

The multiple-methods approach is preferable to a clinical audit. The two nursing homes were keen to improve the quality of care, and the managers were working with the research team to achieve such a goal. However, this might have introduced another level of the Hawthorne effect - one that led to changes in the entire study period of 15 months. To change practices, it is critical to have champions for change through the phases of initiation, development, and implementation..$^{28}$ Service sectors need change champions and leaders to drive quality improvements forward.

Because there were no notifiable communicable diseases between January and December 2014, the team had to draw a convenience sample of five participants who were at higher risk of infections. The small sample limits the interpretation of the results. In home A, frontline staff and management staff were interviewed together in the focus group session. This could have inhibited the frontline staff from expressing their views.

Human and capital investment is necessary to achieve positive outcomes in IPC programmes. ${ }^{6}$ The World Health Organization recommends that regular monitoring and feedback be conducted on hand hygiene to prevent nosocomial infections. ${ }^{29}$ It provides online materials such as the minimum requirements for infection and control programmes ${ }^{30}$ and the infection prevention and control guidance for longterm care facilities in the context of COVID-19. ${ }^{31}$ The Hong Kong Training Portal on Infection Control and Infectious Disease provides three different guidelines on IPC practices in long-term care facilities for three groups: older people, people with disabilities, and those who are mentally incapacitated.

We recommend that nursing homes set up an IPC committee and assign an IPC officer to oversee IPC policies. The nursing homes should strengthen measures to promote the hand hygiene of the residents and staff. Alcohol handrubs should be available in places where there are no handwashing facilities. Both residents and staff should be reeducated and reinforced proper hand hygiene, particularly the use of gloves by staff. The nursing homes should strengthen measures to promote, reeducate, and reinforce proper respiratory hygiene of both residents and staff. For instance, reinforcing residents the message of covering the mouth while coughing and emphasising to the staff that residents should be protected from inhaling dust when beds are made. Nursing homes should strengthen measures to prevent infections and cross-infection among residents. For instance, revisiting the procedures and practices on nasogastric tube feeding and catheterinduced urinary tract infections, and maintaining sufficient distance when residents are having meals together. The nursing homes should benchmark with other residential care homes to gain a better understanding of the standards.

\section{CONCLUSIONS}

Both nursing homes implemented most of the IPC measures stated in the Social Welfare Department code of practice and the Department of Health guidelines. Good practices were observed, although improvement is needed in certain areas. Routines were put in place to ensure that the quality of the services was maintained. No strongly unacceptable or below-standard practices were found. The areas in need of improvement included observance of the practice of handwashing, the provision of better handwashing facilities, the proper use of gloves, and the maintenance of the residents' respiratory hygiene when dining, the prevention of myiasis, and the use of better bedside alert signage. We recommend that nursing homes establish an IPC committee and assign an IPC officer to oversee IPC practices. 
The findings enable residential home operators to identify and prioritise the areas of care that need to be addressed in the context of IPC. Good infection control practices improve the quality of life of residents and reduce healthcare costs.

\section{ACKNOWLEDGEMENTS}

This project was funded by the Social Services Department of the Yuen Yuen Institute, Hong Kong SAR (PolyU assigned number: 5-ZH1F).

\section{CONFLICTS OF INTEREST}

The authors have no conflicts of interest to disclose. $\mathrm{AC}$ is a co-investigator from the Yuen Yuen Institute. The funding body stated only the scope of the investigation and played no role in the design, methods, subject recruitment, data collection, analysis, or preparation of this paper.

\section{REFERENCES}

1. Lee MH, Lee GA, Lee SH, Park YH. A systematic review on the causes of the transmission and control measures of outbreaks in long-term care facilities: back to basics of infection control. PLoS One 2020;15:e0229911. Crossref

2. Koch AM, Eriksen HM, Elstrøm P, Aavitsland P, Harthug S. Severe consequences of healthcare-associated infections among residents of nursing homes: a cohort study. J Hosp Infect 2009;71:269-74. Crossref

3. Montoya A, Cassone M, Mody L. Infections in nursing homes: epidemiology and prevention programs. Clin Geriatr Med 2016;32:585-607. Crossref

4. Woo J, Chau PP. Aging in Hong Kong: the institutional population. J Am Med Dir Assoc 2009;10:478-85. Crossref

5. Montoya A, Mody L. Common infections in nursing homes: a review of current issues and challenges. Aging Health 2011;7:88999. Crossref

6. Flanagan E, Cassone M, Montoya A, Mody L. Infection control in alternative health care settings: an update. Infect Dis Clin North Am 2016;30:785-804. Crossref

7. Smith PW, Bennett G, Bradley S, et al. SHEA/APIC guideline: infection prevention and control in the long-term care facility, July 2008. Infect Control Hosp Epidemiol 2008;29:785-814. Crossref

8. Chen H, Chiu AP, Lam PS, et al. Prevalence of infections in residential care homes for the elderly in Hong Kong. Hong Kong Med J 2008;14:444-50.

9. Choy CS, Chen H,Yau CS, Hsu EK, Chik NY, Wong AT. Prevalence of infections among residents of Residential Care Homes for the Elderly in Hong Kong. Hong Kong Med J 2016;22:347-55. Crossref

10. Heudorf U, Gasteyer S, Müller M, SamoiskiY, Serra N, Westphal T. Prevention and control of catheter-associated urinary tract infections - implementation of the recommendations of the Commission for Hospital Hygiene and Infection Prevention (KRINKO) in nursing homes for the elderly in Frankfurt am Main, Germany. GMS Hyg Infect Control 2016;11:Doc15.

11. Dumyati G, Stone ND, Nace DA, Crnich CJ, Jump RL. Challenges and strategies for prevention of multidrug-resistant organism transmission in nursing homes. Curr Infect Dis Rep 2017;19:18. Crossref

12. Ho ML, Seto WH, Wong LC, Wong TY. Effectiveness of multifaceted hand hygiene interventions in long-term care facilities in Hong Kong: a cluster-randomized controlled trial. Infect Control Hosp Epidemiol 2012;33:761-7. Crossref

13. Ho SS, Tse MM, Boost MV. Effect of an infection control programme on bacterial contamination of enteral feed in nursing homes. J Hosp Infect 2012;82:49-55. Crossref

14. Alexander V, Thomas H, Cronin A, Fielding J, Moran-Ellis J. Mixed Methods. In: Gilbert N, Stoneman P, editors. Researching Social Life. 4th ed. London: Sage; 125-144.

15. Davis DF, Golicic SL, Boerstler CN. Benefits and challenges of conducting multiple methods research in marketing. J Acad Mark Sci 2011;39:467-79. Crossref

16. Gerrish K, Lacey A. The Research Process in Nursing. John Wiley \& Sons; 2010.

17. Social Welfare Department. Code of Practice for Residential Care Homes (Elderly Persons). Hong Kong Special Administrative Region Government. https://www.swd.gov.hk/doc/LORCHE/ CodeofPractice_E_201303_20150313R3.pdf Accessed 2 August 2019.

18. Department of Health. The Guideline on Prevention of Communicable Diseases in Residential Care Home for Elderly (3rd Edition). Hong Kong Special Administrative Region Government. http://www.chp.gov.hk/files/pdf/guidelines_ on_prevention_of_communicable_diseases_in_rche_eng.pdf Accessed 2 August 2019.

19. Social Welfare Department. Care and Attention Homes for the Elderly leaflet. Hong Kong Special Administrative Region Government. https://www.swd.gov.hk/doc/elderly/(P16).pdf Accessed 2 August 2019.

20. Graneheim UH, Lundman B. Qualitative content analysis in nursing research: concepts, procedures and measures to achieve trustworthiness. Nurse Educ Today 2004;24:105-12. Crossref

21. World Health Organization. WHO Guidelines on Hand Hygiene in Health Care. https://www.who.int/infection-prevention/ publications/hand-hygiene-2009/en/ Accessed 1 August 2019.

22. Nicolle LE. Infection prevention issues in long-term care. Curr Opin Infect Dis 2014;27:363-9. Crossref

23. Herzig CT, Stone PW, Castle N, Pogorzelska-Maziarz M, Larson EL, Dick AW. Infection prevention and control programs in United States nursing homes: results of a national survey. J Am Med Dir Assoc 2016;17:85-8. Crossref

24. Alvaran MS, ButzA, Larson E. Opinions, knowledge, and self-reported practices related to infection control among nursing personnel in long-term care settings. Am J Infect Control 1994;22:367-70. Crossref

25. Russell D, Dowding DW, McDonald MV, et al. Factors for compliance with infection control practices in home healthcare: findings from a survey of nurses'knowledge and attitudes toward infection control. Am J Infect Control 2018;46:1211-7. Crossref

26. Beam EL, Gibbs SG, Hewlett AL, Iwen PC, Nuss SL, Smith PW. Method for investigating nursing behaviors related to isolation care. Am J Infect Control 2014;42:1152-6. Crossref

27. Travers J, Herzig CT, Pogorzelska-Maziarz M, et al. Perceived barriers to infection prevention and control for nursing home certified nursing assistants: a qualitative study. Geriatr Nurs 2015;36:355-60. Crossref

28. Gould DJ, Creedon S, Jeanes A, Drey NS, Chudleigh J, Moralejo D. Impact of observing hand hygiene in practice and research: a methodological reconsideration. J Hosp Infect 2017;95:169-74. Crossref

29. Shaw EK, Howard J, West DR, et al. The role of the champion in primary care change efforts: from the State Networks of Colorado Ambulatory Practices and Partners (SNOCAP). J Am Board Fam Med 2012;25:676-85. Crossref

30. World Health Organization. Minimum Requirements for Infection Prevention and Control (IPC) Programmes. https:// www.who.int/infection-prevention/publications/min-req-IPCmanual/en/ Accessed 22 August 2020.

31. World Health Organization. Infection Prevention and Control Guidance for Long-Term Care Facilities in the Context of COVID-19. https://apps.who.int/iris/bitstream/ handle/10665/331508/WHO-2019-nCoV-IPC_long_term_care2020.1-eng.pdf?sequence $=1 \&$ isAllowed=y Accessed 22 August 2020. 